\title{
PRESTRESS LOSSES IN NSM-CFRP FLEXURALLY STRENGTHENED RC BEAMS
}

3

$4 \mathrm{PhD}$ - Engineer

5 ISISE - University of Minho

6 Department of Civil Engineering, Campus de Azurém, 4800-058 Guimarães, Portugal

7

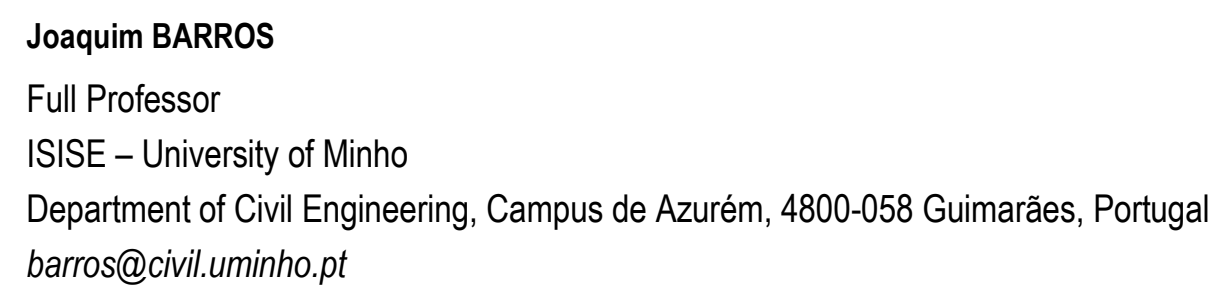

\section{Abstract}

The use of prestressed near surface mounted fibre reinforced polymers (NSM-FRP) has been long acknowledged to be a suitable approach to strengthen and retrofit existing reinforced concrete structures. The application of a certain amount of prestress to the FRP prior to its installation provides a number of benefits, mainly related to crack width and deflection requisites at serviceability limit state conditions. After transferring the prestress to a structural element, some of the existing cracks can be closed, decreasing the vulnerability of the element to corrosion and, a certain amount of deflection can be recovered due to the introduced negative curvature. However, these benefits can only be assured if the prestress is properly preserved over time. In this context, three series of reinforced concrete beams, in a total of 10 beams, were strengthened with a prestressed carbon FRP laminate (CFRP) and monitored for about 40 days. The data obtained from these tests is in this paper presented and analysed. The observed losses of strain in the CFRP laminate were found to be mainly located in the extremities of the bonded length, while in the central zone most of the initial strain was well-preserved over time. Additionally, the highest CFRP strain losses were observed in the first 6 to 12 days after prestress transfer, suggesting that the benefits of prestressed NSM-FRP will not be considerably lost over time.

Keywords: Prestressed CFRP, Near Surface Mounted, Prestress losses, Instantaneous losses, Long term losses.

${ }^{1}$ Corresponding Author. Tel: +351 253315199.

E-mail address: inescosta@civitest.com (Inês G. Costa). 
33 Over the years, the use of fibre reinforced polymers (FRP) for the strengthening of existing 34 structures has been investigated and developed. In fact, FRP bars have already been employed in several structures in Europe, North America and Asia and Australia [1]. However, the use of these materials is not limited to the simple substitution of reinforcing steel by composite bars, but can also be used in repair, rehabilitation and retrofitting operations. Since FRP materials are a practical substitute for conventional reinforcing steel, several authors have also considered the possibility of using them to produce prestressed concrete elements. The use of prestressed FRPs is capable of taking advantage of the superior capacity of the concrete under compression to create a material that is robust both under tension and compression. However, likewise traditional prestress technology using steel bars, the FRPs can experience losses of strain over time and, therefore, this reduction needs to be quantified in order to introduce its effect in the structural design.

In the case of a prestressed NSM-FRP strengthening system, which is usually performed by bonding a prestressed FRP material with a suitable adhesive into a slit made on the concrete cover, besides the losses produced by concrete creep and steel relaxation, other phenomena may compromise the long term effectiveness of the prestress. Considering the common design practice, the relaxation of the prestressing material is typically one of the variables controlling the long term effectiveness of this technology. However, particularly in the case of carbon FRPs (CFRPs), the relaxation is recognized to be insignificant [2-3] and therefore, its contribution can be disregarded. On the other hand, since the prestress transference process from the NSM-FRP to the surrounding concrete relies on the efficacy of a structural adhesive and not on a cementbased grout, the creep of this interface needs to be evaluated. In fact, several authors have already indicated that the creep of the adhesive plays an important role on the long term behaviour of a composite system [3-5], and therefore its evaluation is crucial.

In this scope, some researchers have already reported the experimental behaviour observed in lap shear joints strengthened with externally bonded FRPs (EBR) under sustained stress [6-8], as well as on reinforced concrete beams strengthened with prestressed FRP sheets [3,9]. As a matter of fact, some efforts were already made to analytically predict the loss of prestress in RC elements strengthened with EBR CFRPs, namely by Wang et al. [10]. However, the results obtained using this strengthening system may not reflect the behaviour observed in prestressed FRP applied according to the Near Surface Mounted (NSM). Note that in this last strengthening technique, both surfaces of the FRP actively contribute to the stress transference process and peeling-off failure mechanisms are less likely to occur. Moreover, the adhesive used in NSM 
applications is typically stiffer than the one used in EBR, which may lead to lower strain losses over time.

In order to address the lack of research in the topic of prestressed NSM-FRP strengthening, this paper reports the prestress losses observed in three series of reinforced concrete beams strengthened with a single CFRP laminate up to four different levels of prestress. The prestressing process is described in detail and the observed losses over a conventional time-span are presented and analysed.

\section{Geometry and material properties}

To assess the prestress losses experienced by the prestressed NSM laminates after installation, two reinforced concrete beams of $150 \times 300 \times 2400 \mathrm{~mm}^{3}$ were initially prepared. These beams, which compose Series I, were reinforced with 2 steel bars of $10 \mathrm{~mm}$ diameter both in the tension and compression faces. Closed loop vertical stirrups of $6 \mathrm{~mm}$ diameter spaced at $75 \mathrm{~mm}$ and $25 \mathrm{~mm}$ cover were also installed in order to avoid shear failure when this beams are tested up to failure (a type of test not covered in the present paper). One CFRP laminate of $1.4 \times 20 \mathrm{~mm}^{2}$ cross section was installed in each of the beams in a notch of about $5 \times 25 \mathrm{~mm}^{2}$ opened in the tensile face of the beam. The beams were planned to be executed with a C20/25 concrete strength class, ribbed surface steel bars of $500 \mathrm{MPa}$ yield stress (A500 NR) and a CFRP laminate of $2000 \mathrm{MPa}$ tensile strength and $150 \mathrm{GPa}$ elastic modulus.

In a subsequent phase, two groups of four beams with dimensions of $150 \times 300 \times 4000 \mathrm{~mm}^{3}$ were prepared. The first four beams (Series II) were reinforced with 2 steel bars of $10 \mathrm{~mm}$ diameter in the top and bottom faces and $6 \mathrm{~mm}$ closed loop stirrups were installed with $100 \mathrm{~mm}$ spacing and $30 \mathrm{~mm}$ concrete cover. The last four beams, which composed Series III, were reinforced similarly to the previous Series, but using $12 \mathrm{~mm}$ diameter bars for the longitudinal reinforcement and $8 \mathrm{~mm}$ diameter stirrups. In both of these series, the dimensions of the notch were increased to about $5 \times 30 \mathrm{~mm}^{2}$.

During the preparation process, samples of each of the intervening materials were collected for material characterization and the obtained results are presented in Tables 1 to 3 .

\section{Prestress application and monitoring system}

One of the most crucial tasks of this work is the application of NSM-CFRP prestressed laminates on reinforced concrete elements. For this purpose, a prestress line was designed and installed in the Civil Engineering Laboratory at the University of Minho [11]. Due to the 
specificities of this prestress line, the reinforced concrete beams were flipped upside down, and the strengthening process was applied with the strengthened surface up (Figure 1). The prestress load was applied to the CFRP laminate at an average loading rate of $0.5 \mathrm{kN} / \mathrm{min}$, while during prestress release, to avoid damage in the CFRP-adhesive-concrete interfaces, the release rate was decreased to $0.3 \mathrm{kN} / \mathrm{min}$. A detailed description of the procedure adopted can be found elsewhere [15].

During the whole prestressing process of Series I beams, 9 strain gauges installed in the CFRP laminate were monitored, as depicted in Figure 2. After complete prestress transference, the loss of strain was measured in the CFRP laminate for a period of approximately $1000 \mathrm{~h}$. In the case of Series II and III, the number of monitored strain gauges was reduced to 3, positioned as depicted in Figure 3.

One of the reinforced concrete beams of Series I was strengthened with a CFRP prestressed up to $20 \%$ of its ultimate nominal strain, while the remaining one was strengthened up to $30 \%$. This means that, as the nominal ultimate strain of this material is $2000 / 150=13.333 \%$, a prestress level of $20 \%$ indicates a target strain of $0.2 \times 13.333=2.667 \%$, while a prestress level of $30 \%$ requires the application of $0.3 \times 13.333=4.000 \%$. With respect to the beams of Series II and III, each one was strengthened with a CFRP laminate prestressed up to $20 \%, 30 \%, 40 \%$ and $50 \%$ i.e., using an initial strain level of $2.667 \%$, $4.000 \%$, 5.333\%o and 6.667\%o, respectively. For future reference, these beams are herein labelled as $\mathrm{Si}_{-} \mathrm{j} \%$, where ' $\mathrm{i}$ ' corresponds to the series number (1, 2 or 3$)$ and ' $\mathrm{j}$ ' to the prestress level (20, 30, 40 or 50$)$.

During prestress application, the strain on the CFRP increased almost linearly with the applied load, as depicted in Figure 4 for the case of Series I specimens. The final average pre-strain applied to the beams was in general fairly close to the intended levels. After reaching the expected strain in each of the laminates, the hydraulic system was locked for about 3 days, which corresponds to the curing period of the adhesive. During that time period, undulant movements of the strain signal were registered by all the strain gauges. Note that, due to these fluctuations the strain readings on the CFRP laminates at time of unloading where different from the ones registered immediately after application.

\section{Prestress losses}

\subsection{Instantaneous losses}

Due to the prestress transference process, a decrease of strain is experienced along the bonded length. The highest strain losses are expected in the extremities of the CFRP laminate since at 
that zone the strain is expected to be null. That elevated strain loss gradually decreases towards mid-span where the strain decrease is no longer affected by the transference process but instead by the negative curvature in the beam induced by the prestressed CFRP.

Since, as previously revealed, the strains at time of prestress release were different from the ones at time of prestress application, a summary of the strains registered at the relevant time instants is given in Table 4 for the case of Series I beams. Temperature was found to be the cause of the strain readings fluctuations as it will be demonstrated in section 4.2. Since during loading/unloading the temperature is nearly constant, it was assumed that during the sustained stress period, the effective strains on the materials were constant. Therefore, the strain before load application is null by default, while the strain immediately after application is denoted by $\varepsilon_{p}$ in Table 4. In the subsequent columns, the strain before prestress release, $\varepsilon_{p}^{\prime}$, and after prestress release, $\varepsilon_{f}$, are also reported. For future reference, it is visible in Table 4 that, in the case of S1_20\%, all the strain readings increased from prestress application to prestress release, as did the temperature. Inversely, the CFRP laminate in S1_30\% experienced a decrease in installed strain similarly to the environmental temperature. According to the values reported in this table, it is remarkable that most CFRP strain gauges experienced relatively low strain losses, $\Delta \varepsilon_{p} / \varepsilon_{p} \times 100$, where $\Delta \varepsilon_{p}=\varepsilon_{f}-\varepsilon_{p}^{\prime}$. In fact, the percentage of strain losses in the strain gauges positioned at a distance from the bond extremity higher than $125 \mathrm{~mm}$ was about $1 \%$ in $\mathrm{S} 1 \_20 \%$ and 2\% in S2_30\%.

The same analysis of strains was performed for the case of the beams belonging to Series II and III and these results are reported in Tables 5 and 6. Similarly to the first two beams, the strain on the CFRP increased with the environmental temperature during the sustained load period.

The strain decrease profile during unloading is depicted in Figure 5 for the case of Series I beams. Note that to improve the interpretation of this graph, the strain recovery of the strain gauge placed outside the bonded length is not fully presented since it decreased to approximately zero when the applied load becomes null, as expectable. According to Figure 5, the most elevated strain losses are clearly located in the strain gauge installed at $25 \mathrm{~mm}$, as already reported in Table 4 . In the case of $\mathrm{S} 1 \_30 \%$, the strain gauge installed at $75 \mathrm{~mm}$ also displays a significant strain loss, although before release, this precise strain gauge already demonstrated a considerably lower strain reading (3.672\%o at $75 \mathrm{~mm}$ versus $3.802 \%$ \% $3.892 \%$ o in the remaining strain gauges). In any case, the load-strain profile of this strain gauge is fairly parallel to the one installed in a symmetrical position, $2025 \mathrm{~mm}$. 

governed by the purpose of validating the symmetry of the process of prestress application and release. If Figure 2 is analyzed, it is visible that both the strain gauge at $75 \mathrm{~mm}$ and at $2025 \mathrm{~mm}$ are both located $75 \mathrm{~mm}$ from the nearest unbonded section $(2100 \mathrm{~mm}-2025 \mathrm{~mm}=75 \mathrm{~mm})$. The same happens in the case of the strain gauges at $125 \mathrm{~mm}$ and $1975 \mathrm{~mm}$. For that reason, the strain evolution during prestress release in those symmetric positions is depicted in Figure 6. Observing these pictures, it is clear that the strain loss at $125 \mathrm{~mm}$ and $1975 \mathrm{~mm}$ was in each beam practically the same. Regarding the relationship between the strains at $2025 \mathrm{~mm}$ and $75 \mathrm{~mm}$, although they are relatively parallel to the previous curves (1975 mm versus $125 \mathrm{~mm}$ ), a divergent tendency is observed between S1_20\% and S1_30\%. While in S1_20\%, the higher strain loss is registered on the strain gauge placed at $2025 \mathrm{~mm}$ (passive end side), in S1_30\% the largest strain loss is observed at $75 \mathrm{~mm}$ (active end side). This discrepancy is believed to be related with the difficulty of assuring a proper adhesive penetration in the groove. Therefore, if voids were formed within the groove, the effective bonded length which absorbs the prestress load transference may have been inaccurately provided in one, or both, of the CFRP extremities.

\subsection{Long term losses}

After the prestress load applied to the CFRP laminate has been transferred to the beams, all the strains were continuously monitored. Again, undulant movements of the strains were detected over time. To better demonstrate this behaviour, Figure 7 depicts the strain and temperature readings in the beams prestressed at $20 \%$. Note that in the first 2.5 days after prestress release, the strain readings in S1_20\% fluctuated significantly over time (Figure 7a) following the same trend of the environmental temperature profile, depicted in Figure 7b. However, regarding S2_20\%, the strain level was virtually preserved over time, similarly to the environmental temperature. Therefore, as demonstrated in Figure 7c, the mid-span strain in S1_20\% exhibited

186 a nearly linear relationship with temperature while S2_20\% appears to be uninfluenced by temperature during this period.

188 The raw data obtained i.e., the original data prior to the removal of the environmental effects, is 189 depicted in the left-hand side of Figures $8 \mathrm{a}$ and $8 \mathrm{~b}$. Observing, for example, the strain registered 190 in S1_20\% until about 6 days of age, it is visible that most of the strain gauges recovered nearly 191 the totality of their initial strain, at time of prestress transfer, which is unrealistic. Moreover, if 192 S1_30\% is taken as example, the same observation can be made not only shortly after prestress transfer, but also after about 30 days, which is even less realistic. Based on the conclusions drawn from Figure 7 and the observation of these unrealistic strain recoveries, it was decided to assume that the mid-span strain was preserved over time, and the variation of this strain signal was used to remove the noise recorded in the remaining strain gauges. This noise removal 
strategy can be described by Eq. 0 . The result produced by this noise removal strategy is depicted on the right-hand side of Figures $8 \mathrm{a}$ and $8 \mathrm{~b}$.

$$
\varepsilon_{\text {corrected }}(t)=\varepsilon_{\text {original }}(t)-\left(\varepsilon_{1050 \mathrm{~mm}}(t)-\varepsilon_{1050 \mathrm{~mm}}(0)\right)
$$

where $\varepsilon_{\text {corrected }}(t)$ is the corrected strain recorded at given position at a time instant $t, \varepsilon_{\text {original }}(t)$ is the original strain recorded at the same position and at the same time instant $t$, and $\varepsilon_{1050 \mathrm{~mm}}(0)$ and $\varepsilon_{1050 \mathrm{~mm}}(t)$ are the strains recorded in the strain gauge located at mid-span immediately after prestress release $(t=0)$ and at the time instant $t$, respectively. For the case of Series II and III beams, the subscript ' $1050 \mathrm{~mm}$ ' does not apply and should be renamed as ' $1850 \mathrm{~mm}$ '. It should be noted that the use of this equation is limited to normal environmental temperature conditions, under which the adhesive properties and its bond performance to concrete can be assumed unchanged. If during the tests the environmental temperature approaches to the glass transition temperature of the adhesive, the degradation of this bonding agent, namely due to the increase in deformability and the loss of chemical interaction with the CFRP and concrete, can be significant. In this case the proposed equation is no longer applicable.

Analysing the strain evolution on the CFRP of S1_20\% after performing the strain correction (right-hand side of Figure 8a), it is visible that the majority of the strain gauges did not experience significant losses over time. The sensor exhibiting higher strain loss is, as expected, the one installed at $25 \mathrm{~mm}$ from the loaded-end. In this section $(25 \mathrm{~mm})$, the installed strain became relatively stable after 6 days. Regarding the strain gauges at $75 \mathrm{~mm}$ from the un-bonded zone $(75 \mathrm{~mm}$ and $2025 \mathrm{~mm})$, both demonstrated almost the same strain loss over time, as already observed during the prestress transfer process. Given this observation, it is suggested that the transference length necessary to produce almost null strain loss in this CFRP strengthening system is between $75 \mathrm{~mm}$ and $125 \mathrm{~mm}$.

In S1_30\%, depicted on the right-hand side of Figure 8b, the same observations can be applied. The majority of the strain gauges registered minor strain losses, while at the strain gauge installed at $25 \mathrm{~mm}$ the loss was more expressive. Furthermore, the strain gauges at $75 \mathrm{~mm}$ and $2025 \mathrm{~mm}$ registered a significant decrease of strain over time. However, a discrepancy between these two curves is evident in this beam since, in fact, these have a strain shift of about $0.25 \%$ o from each other. This observation confirms the suspicion that the strain gauges installed at $75 \mathrm{~mm}$ and $2025 \mathrm{~mm}$ may in fact represent non-symmetric positions, as already pointed out.

Regarding the experimental results of the prestressed beams of Series II and III, only the results after environmental correction are presented in Figures 9 and 10. In terms of curve profile, all results are fairly similar to the ones observed in Series I. However, it is worth mentioning that in S2_40\%, depicted in Figure 9c, the strain loss in the strain gauges placed at $25 \mathrm{~mm}$ and $100 \mathrm{~mm}$ 
231 was noticeably high, especially when compared to the strain losses in S2_50\%. Additionally, it

232 is also noteworthy that the strain loss in the strain gauge placed at $100 \mathrm{~mm}$ in S3_50\%

233 (Figure 10d) was particularly large when compared to the strain loss at mid-span (1850 mm).

234 However, a deeper analysis of Table 6 permits concluding that $\varepsilon_{p}$ at mid-span was already

235 abnormally large when compared to the other monitored sections, creating in this case a false

236 impression of excessive strain loss.

237 To fairly compare the results obtained in these beams, the normalized strain in the CFRP 238 laminate was computed, using as reference the applied strain, $\varepsilon_{p}$, reported in Tables 4 to 6 . The 239 result of the normalization of the strains of Series I beams is depicted in Figure 11 where the 240 percentage of applied strain in S1_20\% and S1_30\% is reported side by side. The strain loss in 241 the most central strain gauges $(200 \mathrm{~mm}, 850 \mathrm{~mm}$ and $1050 \mathrm{~mm})$ is notoriously low since 242 98\% 99\% of CFRP strain was retained in S1_20\% over time, while in S1_30\% that percentage 243 was slightly lower and about 97\% 98\%. For the strain gauge at $25 \mathrm{~mm}$ from the unbonded zone 244 this plot shows that after strain stabilization, S1_20\% retained about $64 \%$ of the strain initially 245 applied, while S1_30\% was able of preserving about $69 \%$ of the initial value. Regarding the 246 strain gauges installed at $75 \mathrm{~mm}$ from the unbonded zone, extraneous readings were obtained. If 247 only the strain gauge at $2025 \mathrm{~mm}$ is analyzed in both beams, the normalized strain in both 248 beams is nearly the same (93\% in S1_20\% and 92\% in S1_30\%). However, in the strain gauges 249 placed at $75 \mathrm{~mm}$, the strain loss in S1_20\% was only about 6\% while in S1_30\% was almost $25014 \%$. These observations confirm that these strain discrepancies may in fact be related to a 251 deficient filling of the groove at time of strengthening and, therefore, an inaccurate labeling of 252 the monitored sections may have occurred.

253 The same analysis was performed with respect to the beams of Series II and III, as depicted in 254 Figures 12 and 13. Comparing the strain profile of S2_20\% and S2_50\% (Figures 12a and 12b), 255 it is visible that both strain gauges placed at $25 \mathrm{~mm}$ exhibited a similar percentage of strain loss. 256 However, the strain gauge placed at $100 \mathrm{~mm}$ exhibited a larger percentage of loss in S2_20\% 257 than in S2_50\%. On the other hand, as previously pointed out, S2_40\% exhibited a strain loss at $258100 \mathrm{~mm}$ considerably larger than all the other beams of this Series.

259 Concerning Series III beams, the normalized strain loss profile of S3_20\% and S3_30\% are 260 practically the same, as suggested by the symmetry observed in Figure 13a. Moreover, S3_40\% 261 still appears to exhibit an abnormal percentage of strain loss in the strain gauges at $25 \mathrm{~mm}$ and $262100 \mathrm{~mm}$, even larger than S3_50\%, which once more suggests that in fact, the positioning of the 263 strain gauges may not correspond to their effective position. 
Regarding the time necessary to attain a stabilized strain profile in these specimens, the beams of Series II and III required a longer period, in general up to 12 days. Even so, a great percentage of strain loss is also observed for about 6 days after prestress release.

\section{Conclusions}

268 In this paper, the procedure used to apply prestressed NSM-CFRP laminates in three series of 269 reinforced concrete beams and the subsequent monitoring of the prestress losses along the 270 CFRP laminate was described and analysed. The desired prestress levels were successfully 271 applied in all of the beams. During the application and subsequent monitoring period, the 272 variation of the environmental temperature was found to be a key parameter to properly assess 273 the effective strain in the different materials/sections.

274 Concerning the instantaneous behaviour of the prestressed beams, all beams registered low 275 levels of strain loss along the majority of the bonded length. The largest losses of prestress in 276 the CFRP sections were registered in the strain gauges located at $25 \mathrm{~mm}$ from the unbonded 277 zone, and were found to occur in the first 6 to 12 days after prestress release. Since negligible 278 strain losses were observed in the CFRP sections located $200 \mathrm{~mm}$ from the unbonded zones in 279 the first series of beams, it can be assumed that for prestress levels lower than $4 \%$, the required 280 transfer length is lower than $125 \mathrm{~mm}$. However, given the reduced number of strain gauges 281 installed on the CFRP laminate, it was not possible to verify this assumption in the beams of 282 Series II and III. Nevertheless, given the low strain loss registered at $100 \mathrm{~mm}$ in the beams 283 prestressed up to 50\%, it can be assumed that the transfer length will not be significantly higher 284 than $100 \mathrm{~mm}$. In any case, this estimation proves that this prestress application procedure was 285 efficiently applied along most of the strengthening length.

\section{Acknowledgments}

287 The research carried out is part of the project PreLami (PTDC/ECM/114945/2009). The first 288 Author acknowledges the support provided by FCT grant, SFRH/BD/61756/2009. The authors 289 would also like to acknowledge S\&P for providing the epoxy adhesive and FRP laminate and 290 Unibetão, Pregaia and Casais for providing the reinforced concrete beams.

\section{References}

292 [1] ACI 440R-96 (1996). "State-of-the-Art Report on Fiber Reinforced Plastic (FRP) Reinforcement for Concrete Structures." American Concrete Institute (ACI), 68 pp. 
[2] Lopez-Anido, R. A. and Naik, T. R. (2000). "Emerging Materials for Civil Engineering Infrastructure - State of the Art." American Society of Civil Engineers, Reston, Virginia, US.

[3] Wang, W.-W.; Dai, J.-G.; Harries, K. A. and Bao, Q.-H. (2012). "Prestress Losses and Flexural Behavior of Reinforced Concrete Beams Strengthened with Posttensioned CFRP Sheets.” Journal of Composites for Construction, ASCE, 16(2), 207-216.

[4] Nordin, H. and Täljsten, B. (2006). "Concrete Beams Strengthened with Prestressed Near Surface Mounted CFRP.” Journal of Composites for Construction, ASCE, 10(1), 60-68.

[5] Quantrill, R. J. and Hollaway, L. C. (1998). "The flexural rehabilitation of reinforced concrete beams by the use of prestressed advanced composite plates." Composites Science and Technology, Elsevier, 58(8), 1259-1275.

[6] Choi, K.-K.; Meshgin, P.; Taha, M. M. R. (2007). "Shear creep of epoxy as the concreteFRP interfaces." Composites Part B: Engineering, Elsevier, 38(5-6), 772-780.

[7] Diab, H. and Wu, Z. (2007). "A linear viscoelastic model for interfacial long-term behavior of FRP-concrete interface." Composites Part B: Engineering, Elsevier, 39(4), $722-730$.

[8] Meaud, C.; Jurkiewiez, B. and Ferrier, E. (2011). "Investigation of creep effects in strengthened RC structures through double lap shear testing." Composites Part B: Engineering, Elsevier, 42(3), 359-366.

[9] Wu, Z. and Diab, H. (2007). "A linear viscoelastic model for interfacial long-term behavior of FRP-concrete interface." Journal of Composites for Construction, ASCE, 11(5), 477-486.

[10] Wang, W.W.; Dai, J.G.; Harries, K.A. and Zhang, L. (2014). "Prediction of prestress losses in RC beams externally strengthened with prestressed CFRP sheets/plates." Journal of Reinforced Plastics and Composites, SAGE, 33(8), 699-713.

[11] Costa, I. G and Barros, J. A. O. (2012). "Design and development of a hydraulic-electromechanical system to apply pre-stressed CFRP laminates according to the NSM technique in laboratory conditions." Technical report no. 12-DEC/E-10, University of Minho, Guimarães, Portugal, 59 pp.

[12] ISO 527-5 (1997). "Plastics - Determination of tensile properties - Part 5: Test conditions for unidirectional fibre-reinforced plastic composites." International Organization for Standardization, $12 \mathrm{pp}$. 
326 [13] E365 (1993). "Hardened Concrete - Determination of the modulus of elasticity of concrete in compression.” National Laboratory for Civil Engineering Specification, 2 pp (in Portuguese).

329 [14] NPEN10002-1 (1990). "Metallic materials - Tensile testing. Part 1: Method of test (at ambient temperature)." European Committee for Standardization (CEN), 34 pp. (in Portuguese)

[15] Costa, I. G. (2014). "Prestressed Carbon Fibre laminates applied according to Near Surface Mounted technique to increase the flexural resistance of Reinforced Concrete beams." PhD thesis, University of Minho, Guimarães, Portugal. 
336 Figure 1 - Prestress beam preparation: (a) installation of the strain gauges, (b) insertion of the adhesive.

337 Figure 2 - Positioning of the strain gauges in the CFRP laminate - Series I.

338 Figure 3 - Positioning of the strain gauges in the CFRP laminate - Series II and III.

339 Figure 4 - Prestress load versus average CFRP strain during loading - Series I.

340 Figure 5 - Load versus strain in the CFRP during prestress release: (a) S1_20\% and (b) S1_30\%.

341 Figure 6 -Strain evolution during prestress release in symmetrical CFRP strain gauges: (a) S1_20\% and $342 \quad$ (b) $S 1 \_30 \%$.

343 Figure 7 - Mid-span CFRP strains after prestress release: (a) strain versus time, (b) temperature versus time and $344 \quad$ (c) strain versus temperature.

345 Figure 8 - Original and corrected CFRP strains: (a) S1_20\% and (b) S1_30\%.

346 Figure 9 - Corrected CFRP strains: (a) S2_20\%, (b) S2_30\%, (c) S2_40\% and (d) S2_50\%.

347 Figure 10 - Corrected CFRP strains: (a) S3_20\%, (b) S3_30\%, (c) S3_40\% and (d) S3_50\%.

348 Figure 11 - Normalized strains over time in S1_20\% (left) and S1_30\% (right).

349 Figure 12 - Normalized strains over time in: (a) S2_20\% (left) and S2_30\% (right) and (b) S2_40\% (left) and 350 S2_50\% (right).

351 Figure 13 - Normalized strains over time in: (a) S3_20\% (left) and S3_30\% (right) and (b) S3_40\% (left) and 352 S3_50\% (right). 


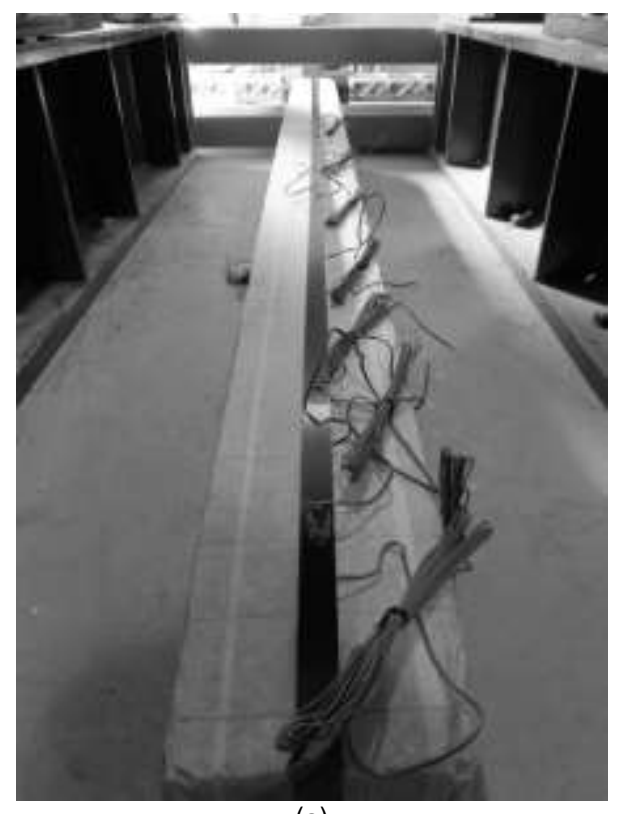

(a)

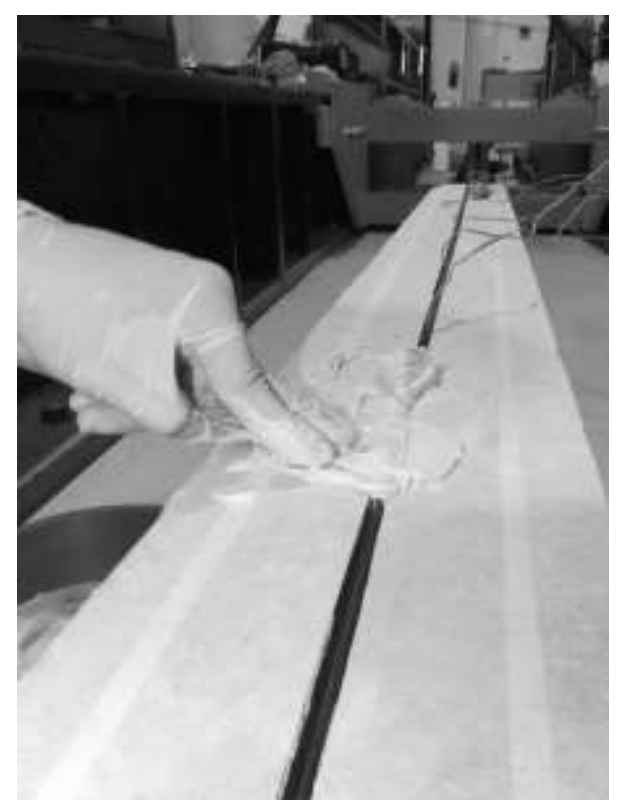

(b)

Figure 1 - Prestress beam preparation: (a) installation of the strain gauges, (b) insertion of the adhesive. 


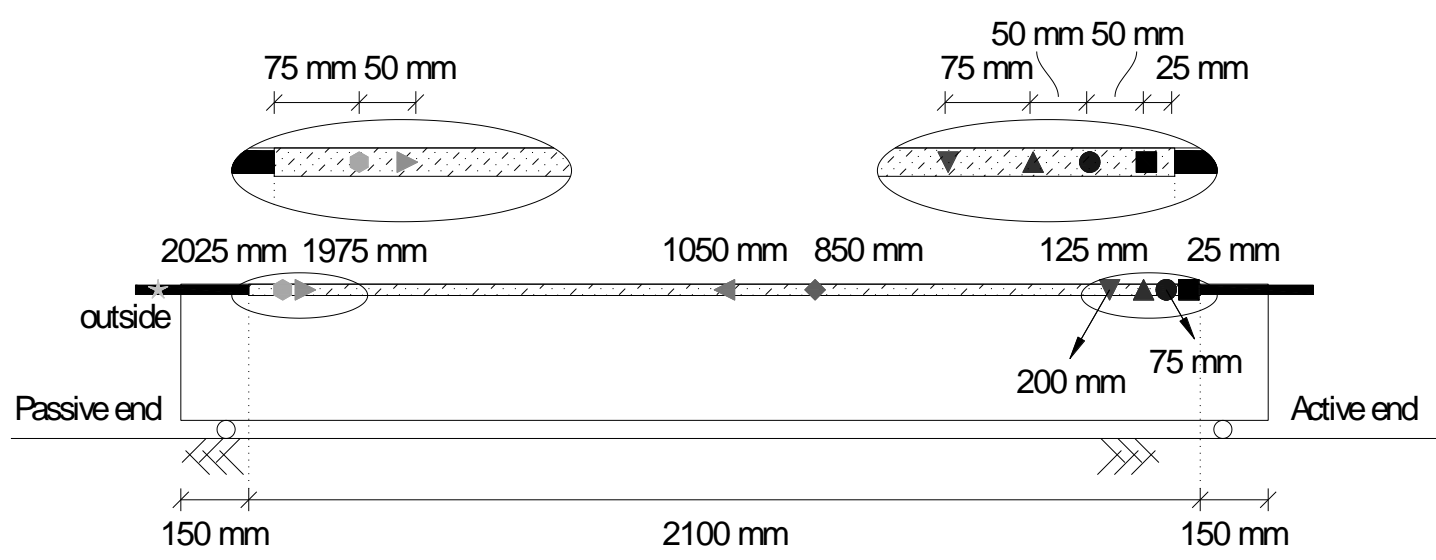

Figure 2 - Positioning of the strain gauges in the CFRP laminate - Series I. 


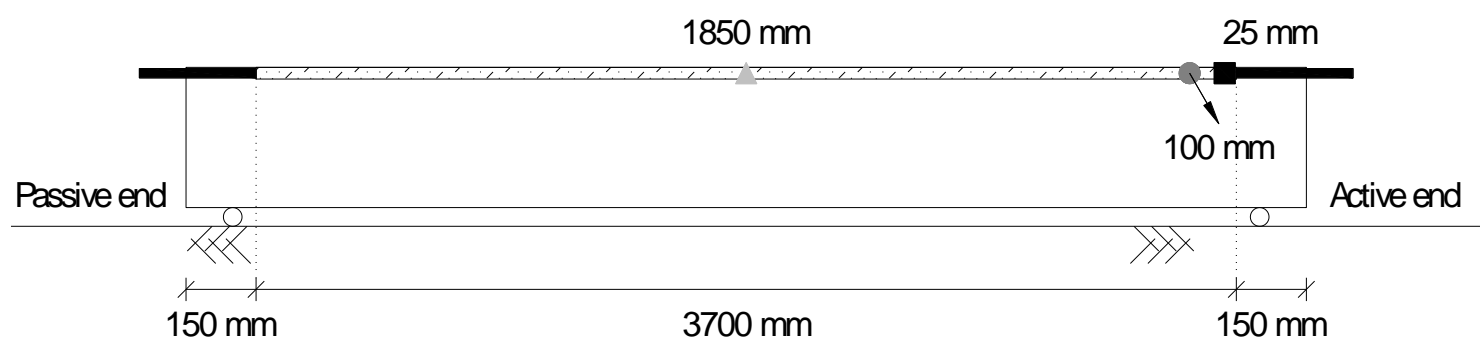

Figure 3 - Positioning of the strain gauges in the CFRP laminate - Series II and III. 


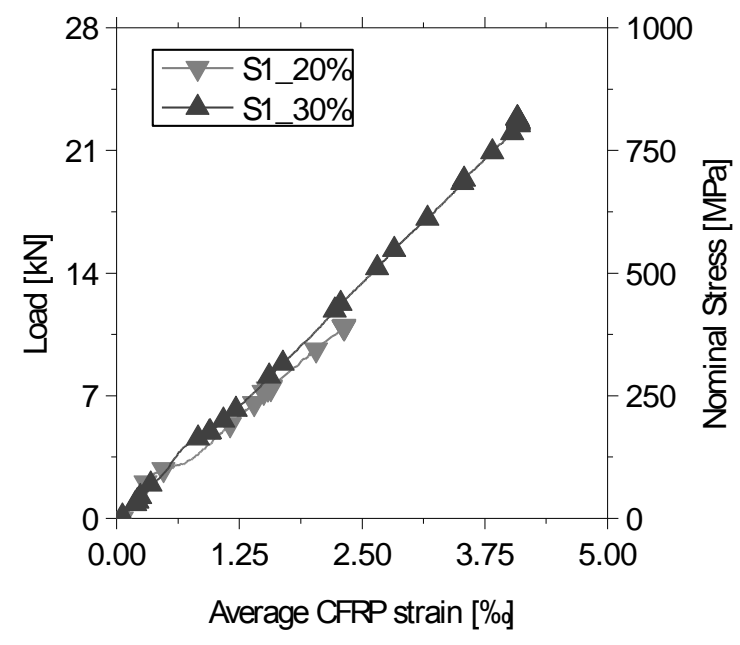




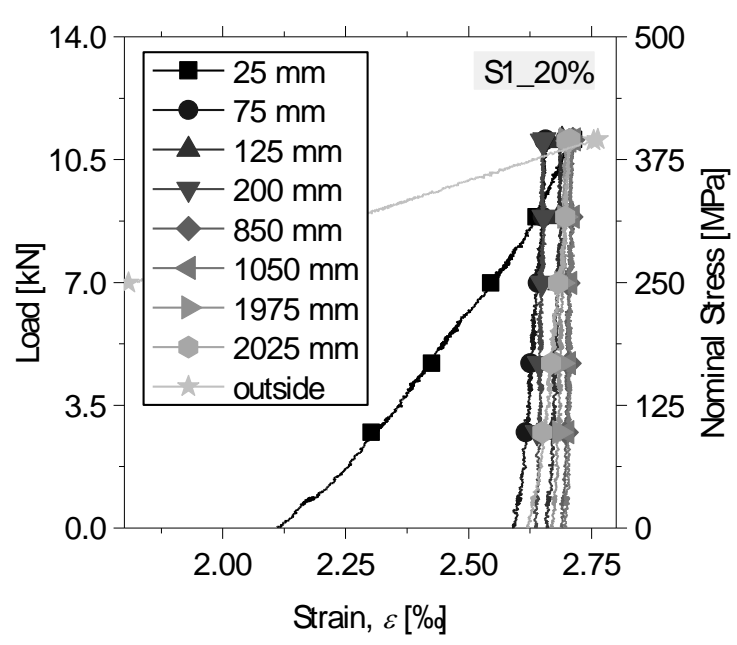

(a)

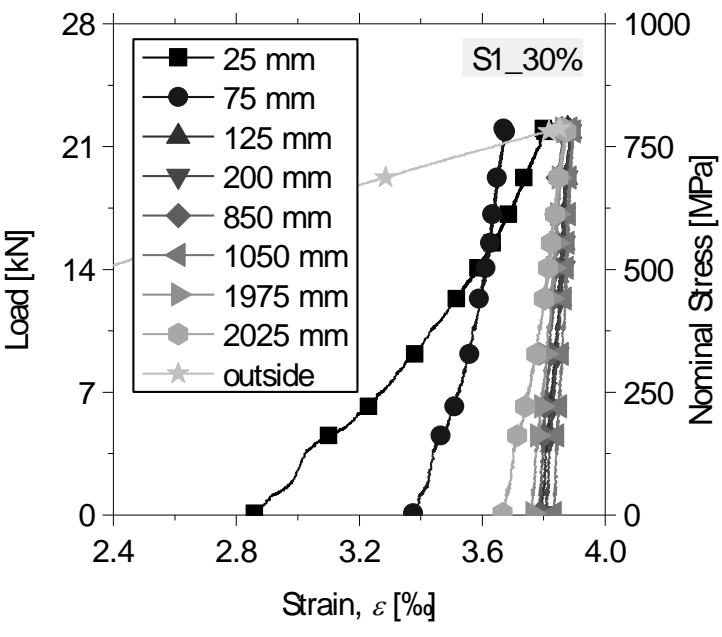

(b)

Figure 5 - Load versus strain in the CFRP during prestress release: (a) S1_20\% and (b) S1_30\%. 


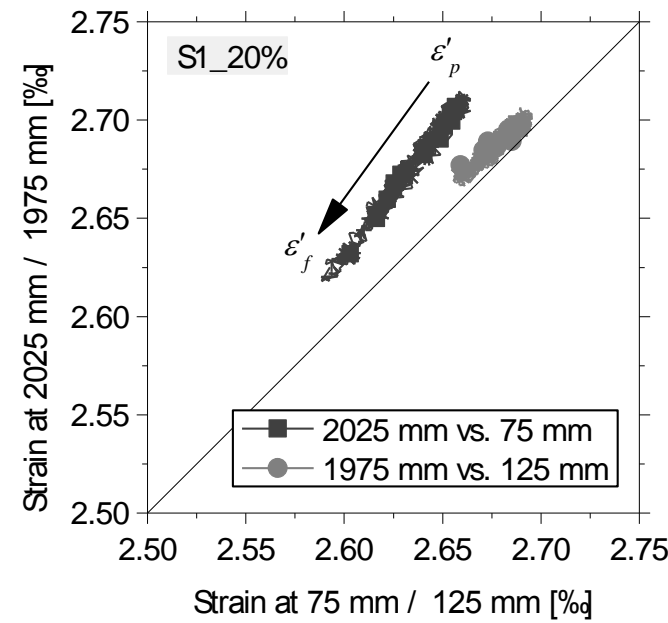

(a)

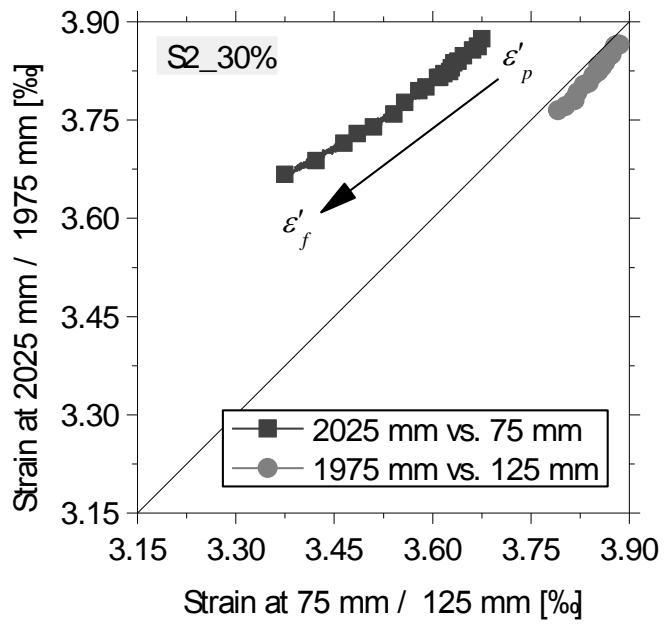

(b)

Figure 6 - Strain evolution during prestress release in symmetrical CFRP strain gauges:

(a) $51 \_20 \%$ and (b) $51 \_30 \%$. 


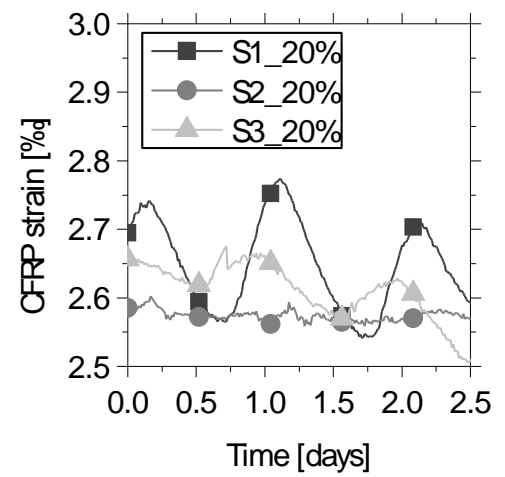

(a)

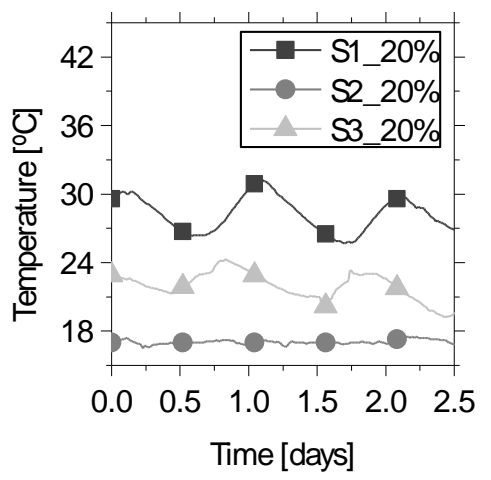

(b)

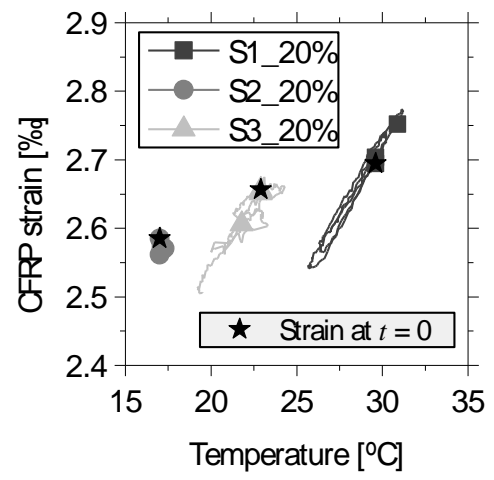

(c)

Figure 7 - Mid-span CFRP strains after prestress release: (a) strain versus time, (b) temperature versus time and (c) strain versus temperature. 


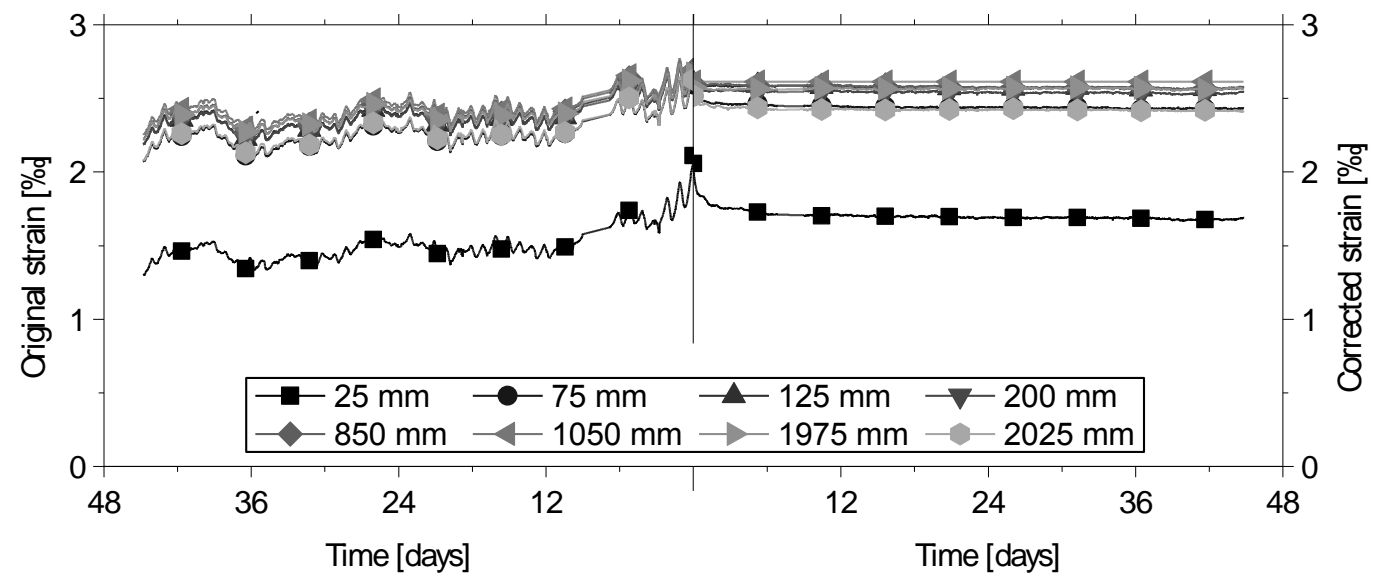

(a)

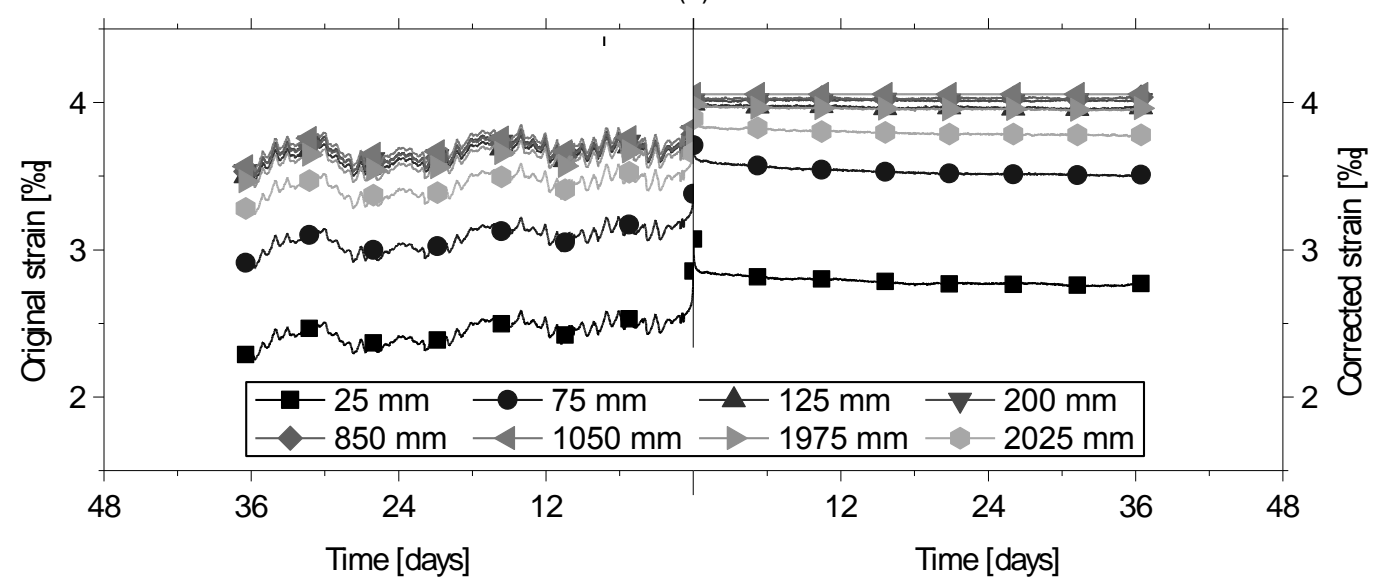

(b)

Figure 8 - Original and corrected CFRP strains: (a) S1_20\% and (b) S1_30\%. 


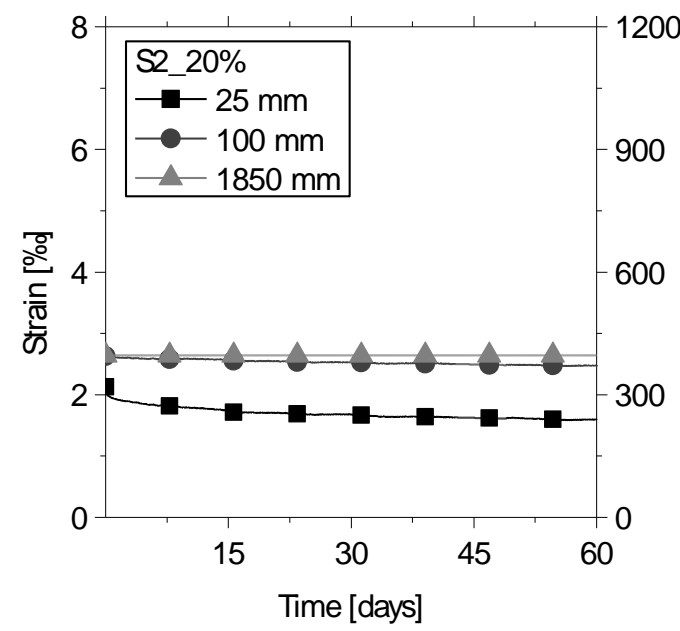

(a)

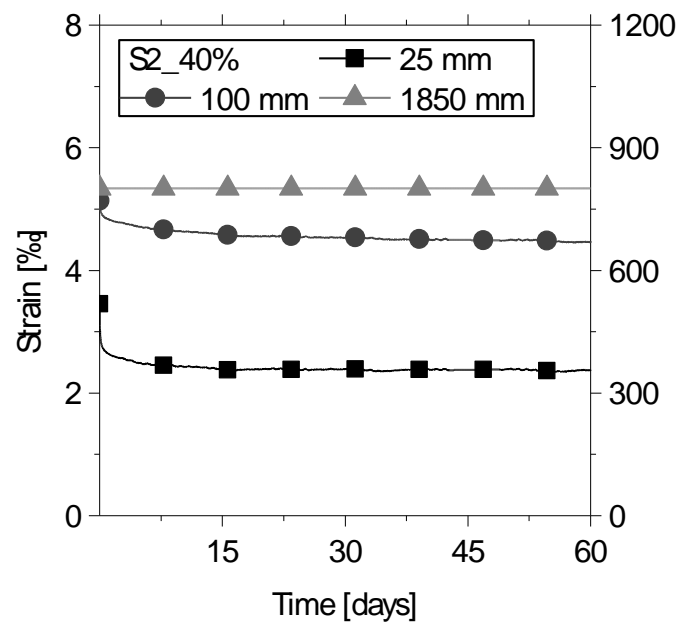

(c)

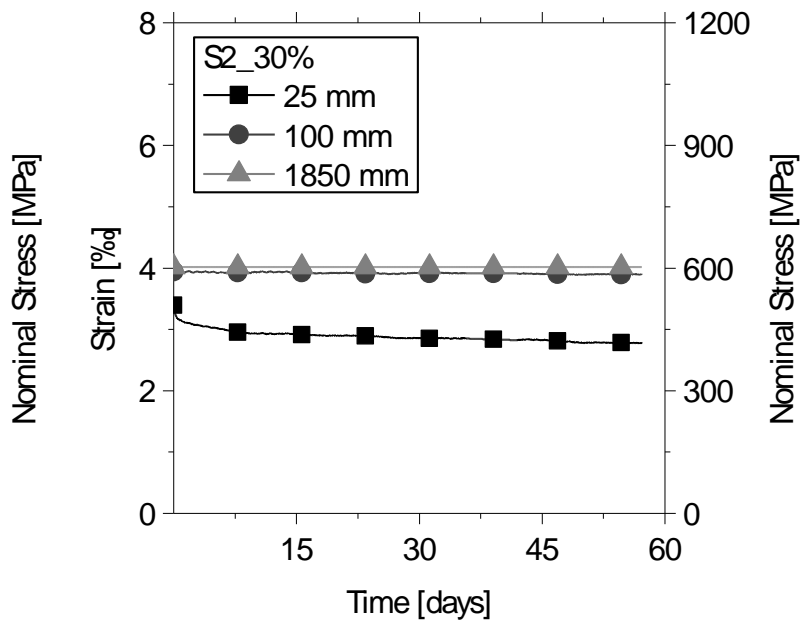

(b)

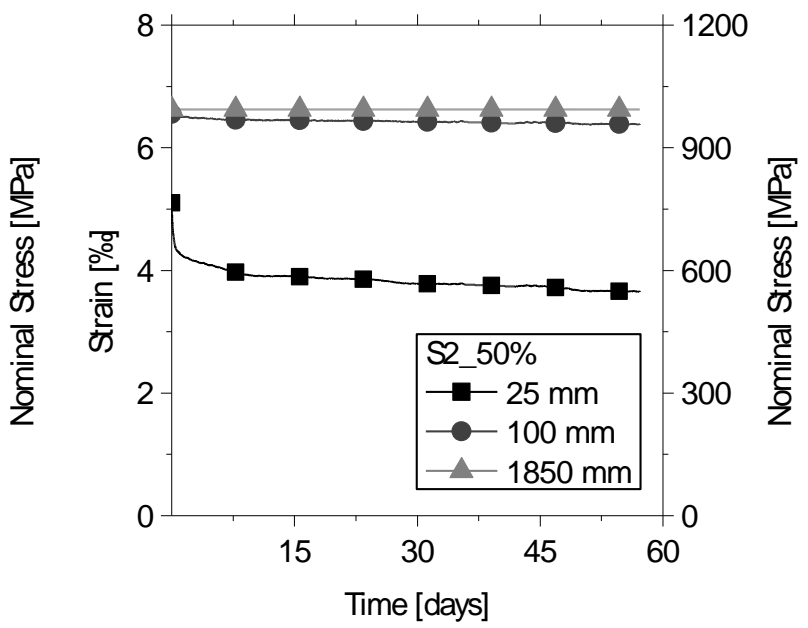

(d)

Figure 9 - Corrected CFRP strains: (a) S2_20\%, (b) S2_30\%, (c) S2_40\% and (d) S2_50\%. 


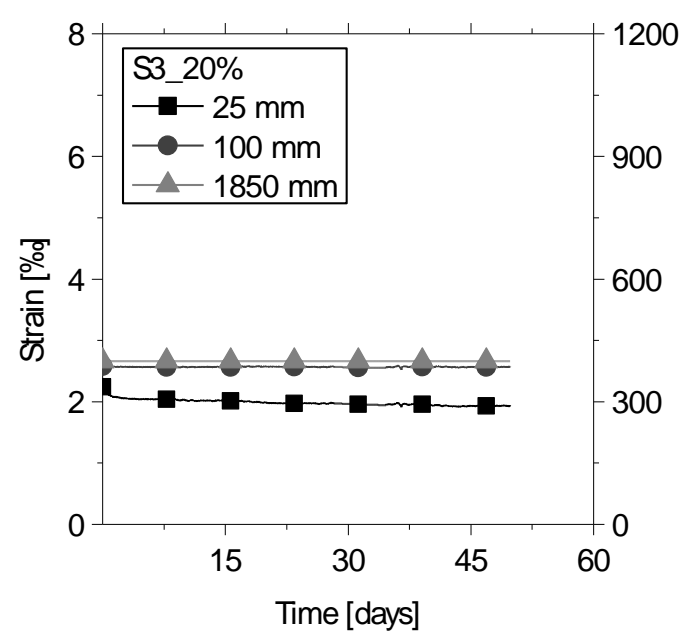

(a)

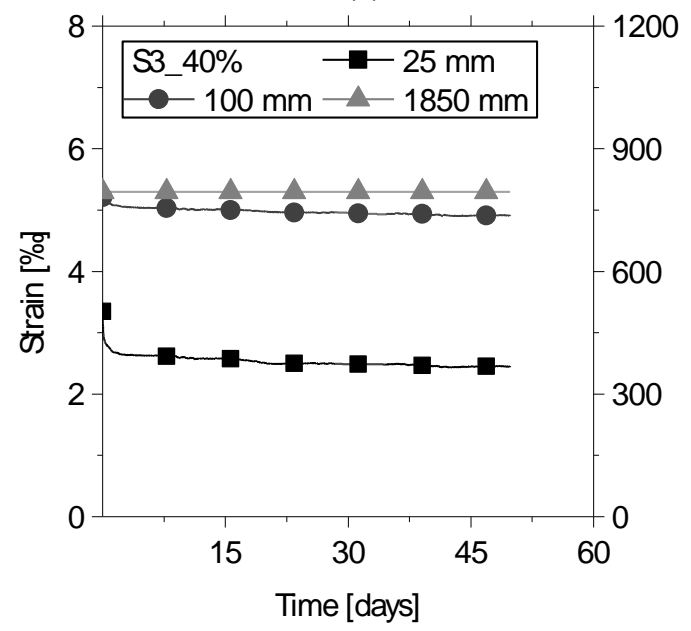

(c)

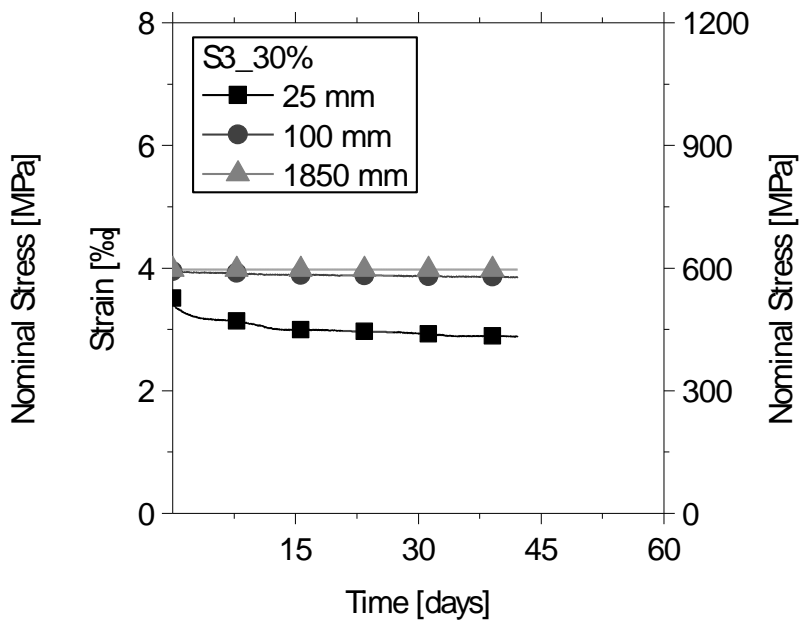

(b)

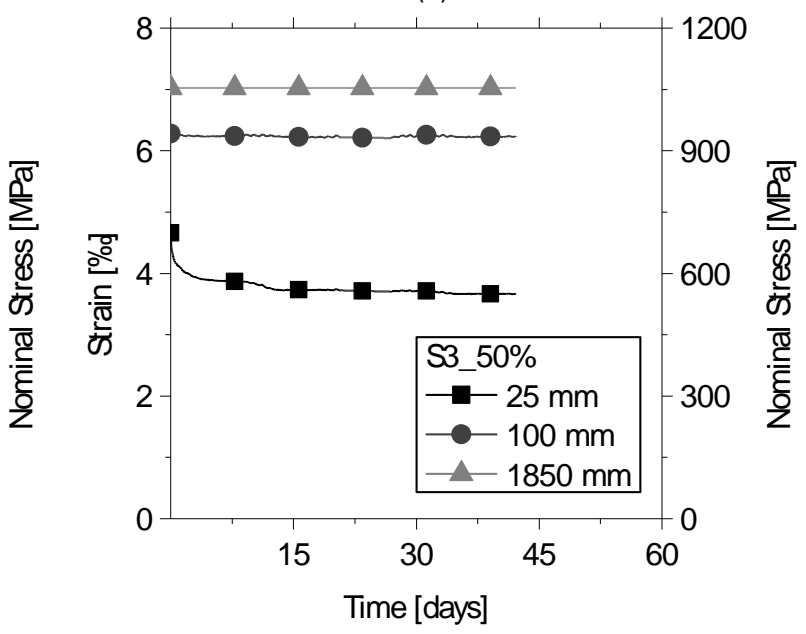

(d)

Figure 10 - Corrected CFRP strains: (a) S3_20\%, (b) S3_30\%, (c) S3_40\% and (d) S3_50\%. 


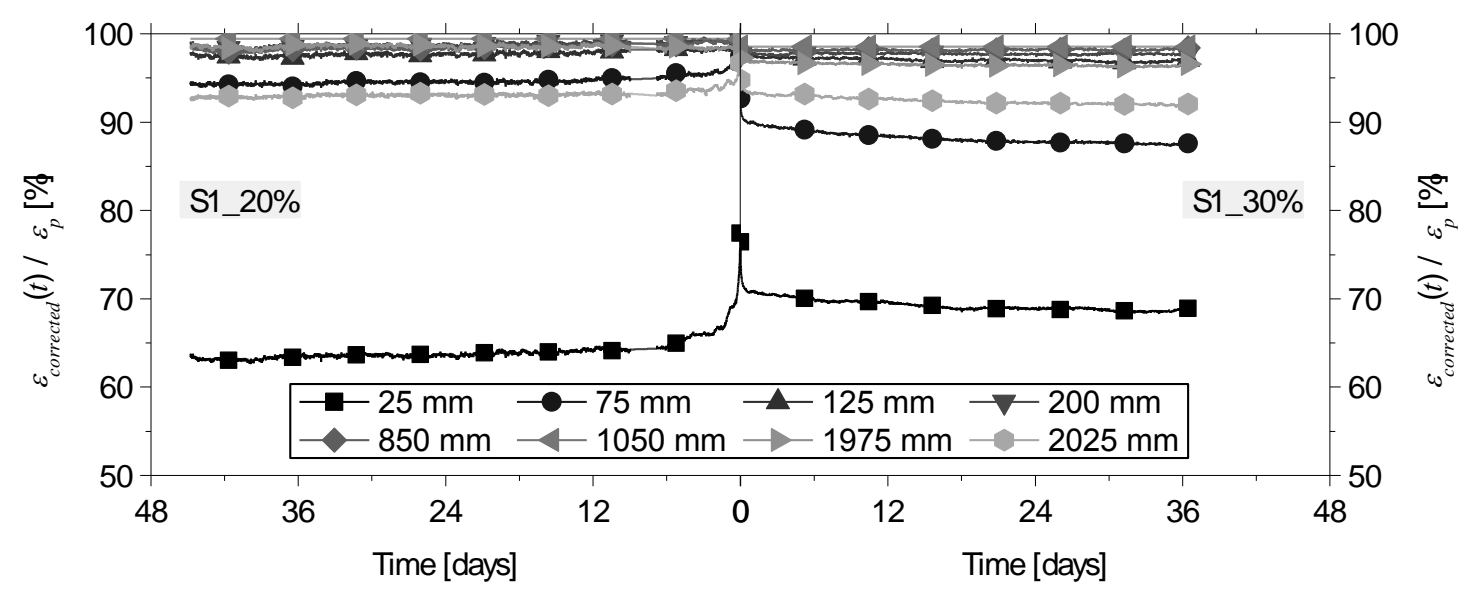

Figure 11 - Normalized strains over time in S1_20\% (left) and S1_30\% (right). 


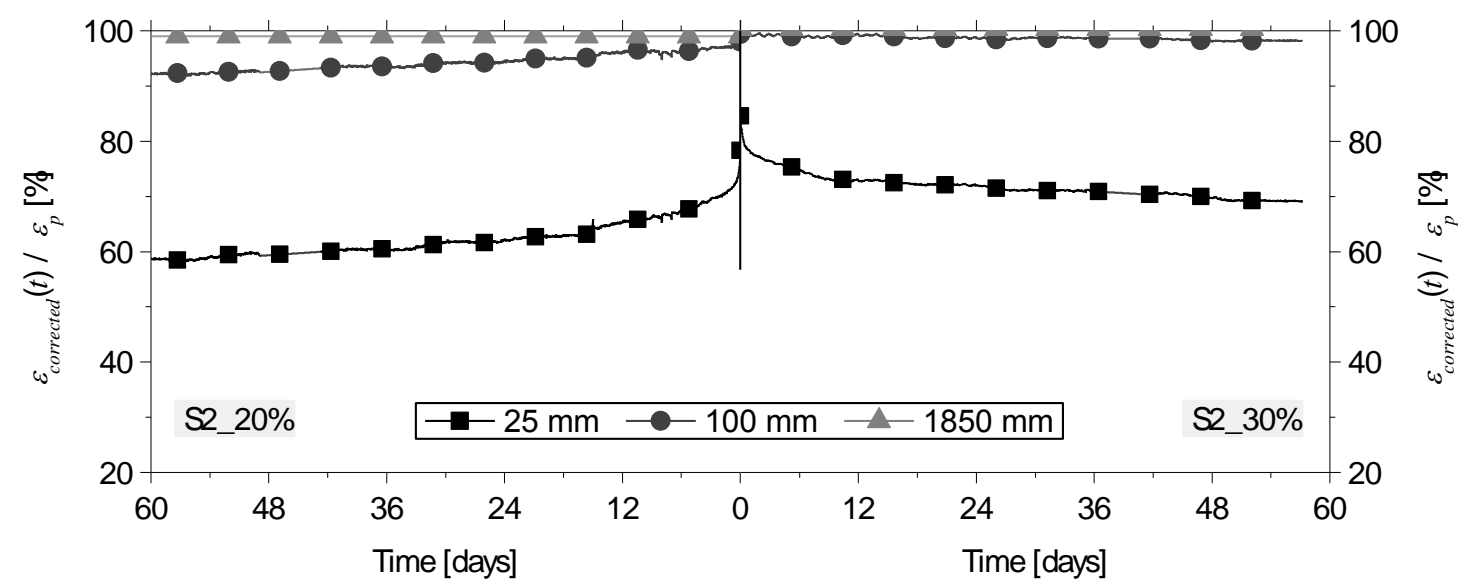

(a)

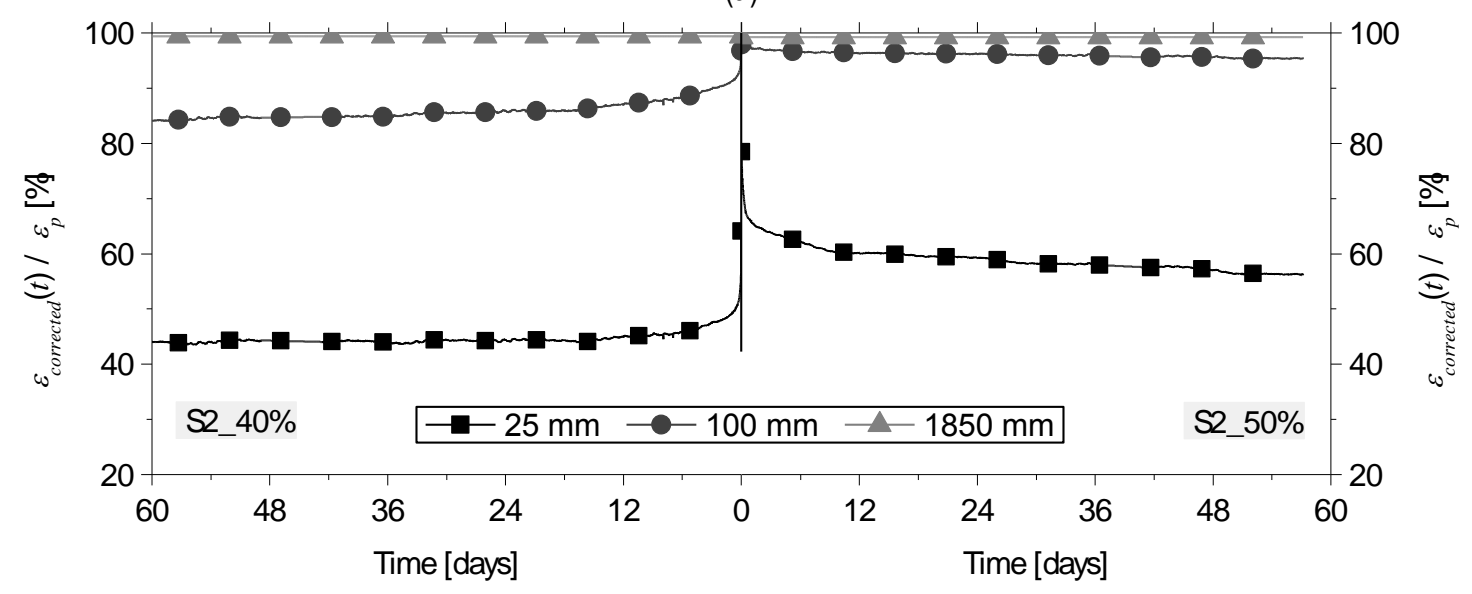

(b) (b) S2_40\% (left) and S2_50\% (right). 


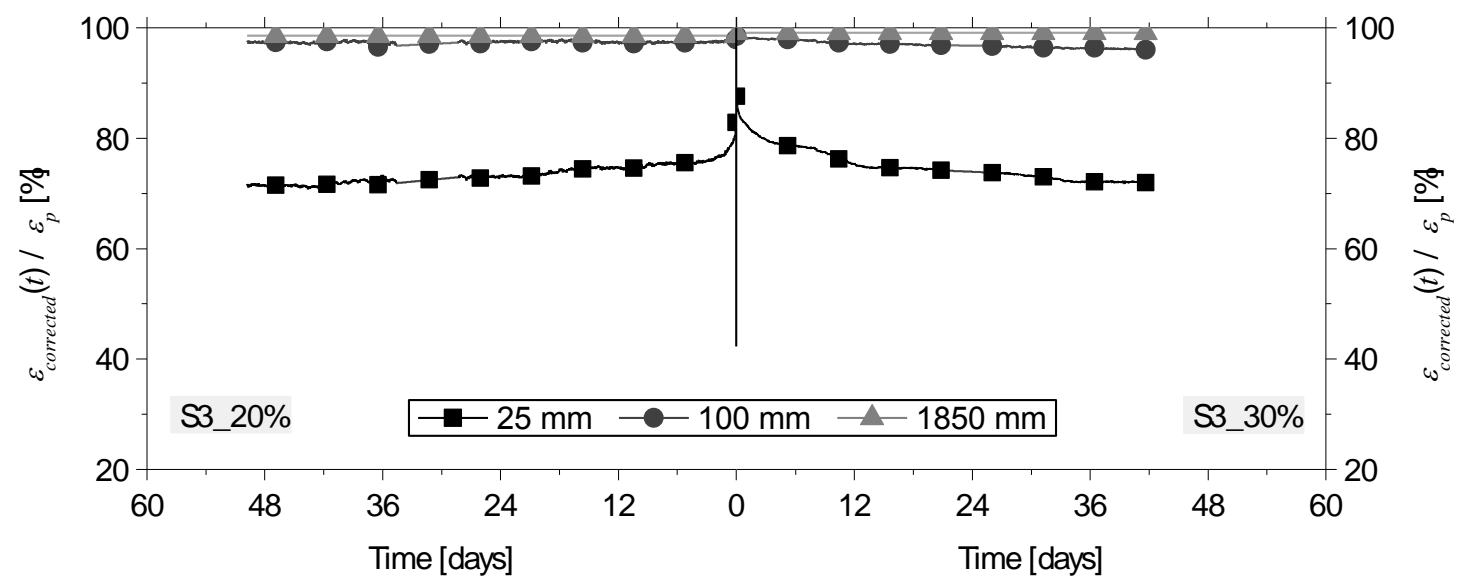

(a)

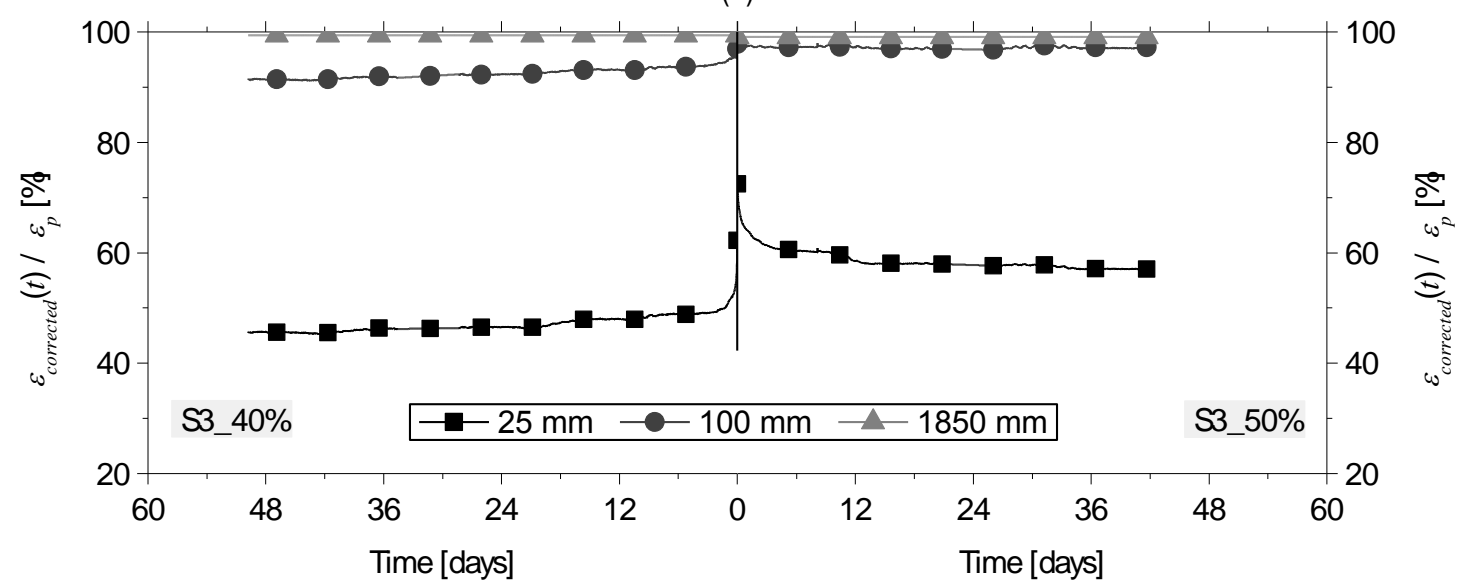

(b)

Figure 13 - Normalized strains over time in: (a) S3_20\% (left) and S3_30\% (right) and

(b) S3_40\% (left) and S3_50\% (right). 


\section{LIST OF TABLES}

372 Table 1 - Material properties - Series I [11-13].

373 Table 2 - Material properties - Series II [12-13].

374 Table 3 - Material properties - Series III [12-13].

375 Table 4 - Instantaneous prestress losses - Series I.

376 Table 5 - Instantaneous prestress losses - Series II.

377 Table 6 - Instantaneous prestress losses - Series III.

378 


\begin{tabular}{|c|c|c|c|c|c|c|c|c|c|c|}
\hline \multirow{3}{*}{ Specimen } & \multirow{2}{*}{\multicolumn{2}{|c|}{ CFRP }} & \multirow{2}{*}{\multicolumn{2}{|c|}{ Concrete }} & \multicolumn{6}{|c|}{ Reinforcing steel } \\
\hline & & & & & \multicolumn{3}{|c|}{ Longitudinal bars } & \multicolumn{3}{|c|}{ Stirrups } \\
\hline & $\begin{array}{c}E_{f} \\
{[\mathrm{GPa}]}\end{array}$ & $\begin{array}{c}f_{f} \\
{[\mathrm{MPa}]}\end{array}$ & $\begin{array}{c}E_{c} \\
{[\mathrm{GPa}]}\end{array}$ & $\begin{array}{c}f_{c} \\
{[\mathrm{MPa}]}\end{array}$ & $\begin{array}{c}E_{s} \\
{[\mathrm{GPa}]}\end{array}$ & $\begin{array}{c}f_{y} \\
{[\mathrm{MPa}]}\end{array}$ & $\begin{array}{c}f_{u} \\
{[\mathrm{GPa}]}\end{array}$ & $\begin{array}{c}E_{s} \\
{[\mathrm{GPa}]}\end{array}$ & $\begin{array}{c}f_{y} \\
{[\mathrm{MPa}]}\end{array}$ & $\begin{array}{c}f_{u} \\
{[\mathrm{GPa}]}\end{array}$ \\
\hline 1 & 167 & 1925 & 29.10 & 33.0 & 203 & 515 & 635 & 218 & 629 & 703 \\
\hline 2 & 167 & 1970 & 25.74 & 31.4 & 200 & 514 & 635 & 215 & 605 & 694 \\
\hline 3 & 170 & 1859 & $-\S$ & $-\S$ & 210 & 519 & 640 & 228 & 618 & 703 \\
\hline 4 & 170 & 1970 & $-\S$ & $-\S$ & 211 & 519 & 640 & 209 & 598 & 684 \\
\hline 5 & 170 & 1941 & - & - & 216 & 513 & 632 & - & - & - \\
\hline Average & 169 & 1933 & 27.4 & 32.2 & 208 & 516 & 636 & 218 & 613 & 696 \\
\hline Standard Deviation & 2 & 46 & 2.4 & 1.1 & 6 & 3 & 4 & 8 & 14 & 9 \\
\hline cov & $1 \%$ & $2 \%$ & $9 \%$ & $3 \%$ & $3 \%$ & $1 \%$ & $1 \%$ & $4 \%$ & $2 \%$ & $1 \%$ \\
\hline
\end{tabular}

$\S$ Some of the samples casted were mistakenly used for other purposes. 
Table 2 - Material properties - Series II [13-14].

\begin{tabular}{|c|c|c|c|c|c|c|c|c|}
\hline \multirow{3}{*}{ Specimen } & \multirow{2}{*}{\multicolumn{2}{|c|}{ Concrete }} & \multicolumn{6}{|c|}{ Reinforcing steel } \\
\hline & & & \multicolumn{3}{|c|}{ Longitudinal bars } & \multicolumn{3}{|c|}{ Stirrups } \\
\hline & $\begin{array}{c}E_{c} \\
{[\mathrm{GPa}]}\end{array}$ & $\begin{array}{c}f_{c} \\
{[\mathrm{MPa}]}\end{array}$ & $\begin{array}{c}E_{s} \\
{[\mathrm{GPa}]}\end{array}$ & $\begin{array}{c}f_{y} \\
{[\mathrm{MPa}]}\end{array}$ & $\begin{array}{c}f_{u} \\
{[\mathrm{GPa}]}\end{array}$ & $\begin{array}{c}E_{s} \\
{[\mathrm{GPa}]}\end{array}$ & $\begin{array}{c}f_{y} \\
{[\mathrm{MPa}]}\end{array}$ & $\begin{array}{c}f_{u} \\
{[\mathrm{GPa}]}\end{array}$ \\
\hline 1 & - & $33.5 \S$ & 197 & 530 & 643 & 216 & 646 & 680 \\
\hline 2 & 43.3 & 50.5 & 204 & 555 & 644 & 213 & 645 & 676 \\
\hline 3 & 38.1 & 42.8 & 201 & 521 & 625 & 208 & 642 & 673 \\
\hline 4 & 39.2 & 50.1 & 212 & 541 & 630 & 216 & 653 & 685 \\
\hline 5 & & & 202 & 544 & 632 & 204 & 653 & 688 \\
\hline Average & 40.2 & 47.8 & 202 & 538 & 634 & 211 & 648 & 680 \\
\hline Standard Deviation & 2.8 & 4.3 & 6 & 12 & 8 & 5 & 5 & 6 \\
\hline cov & $7 \%$ & $9 \%$ & $3 \%$ & $2 \%$ & $1 \%$ & $3 \%$ & $1 \%$ & $1 \%$ \\
\hline
\end{tabular}

$382 \S$ Considered as an outlier and, therefore, not considered in the average calculation. 
Table 3 - Material properties - Series III [13-14].

\begin{tabular}{|c|c|c|c|c|c|c|c|c|}
\hline \multirow{3}{*}{ Specimen } & \multirow{2}{*}{\multicolumn{2}{|c|}{ Concrete }} & \multicolumn{6}{|c|}{ Reinforcing steel } \\
\hline & & & \multicolumn{3}{|c|}{ Longitudinal bars } & \multicolumn{3}{|c|}{ Stirrups } \\
\hline & $\begin{array}{c}E_{c} \\
{[\mathrm{GPa}]}\end{array}$ & $\begin{array}{c}f_{c} \\
{[\mathrm{MPa}]}\end{array}$ & $\begin{array}{c}E_{s} \\
{[\mathrm{GPa}]}\end{array}$ & $\begin{array}{c}f_{y} \\
{[\mathrm{MPa}]}\end{array}$ & $\begin{array}{c}f_{u} \\
{[\mathrm{GPa}]}\end{array}$ & $\begin{array}{c}E_{s} \\
{[\mathrm{GPa}]}\end{array}$ & $\begin{array}{c}f_{y} \\
{[\mathrm{MPa}]}\end{array}$ & $\begin{array}{c}f_{u} \\
{[\mathrm{GPa}]}\end{array}$ \\
\hline 1 & - & 31.4 & 181 & 518 & 626 & 194 & 535 & 641 \\
\hline 2 & 38.54 & 36.0 & 213 & 527 & 625 & 196 & 547 & 645 \\
\hline 3 & 39.27 & 31.2 & 206 & 517 & 622 & 200 & 541 & 646 \\
\hline 4 & 41.38 & 27.8 & 218 & 517 & 624 & - & - & - \\
\hline 5 & - & - & 201 & 521 & 621 & - & - & - \\
\hline Average & 39.7 & 31.6 & 204 & 520 & 624 & 197 & 541 & 644 \\
\hline Standard Deviation & 1.5 & 3.4 & 14 & 4 & 2 & 3 & 6 & 3 \\
\hline cov & $4 \%$ & $11 \%$ & $7 \%$ & $1 \%$ & $0 \%$ & $1 \%$ & $1 \%$ & $0 \%$ \\
\hline
\end{tabular}

384 


\begin{tabular}{|c|c|c|c|c|c|c|c|c|c|c|}
\hline \multirow[b]{2}{*}{ Strain gauge } & \multicolumn{5}{|c|}{ S1_20\% } & \multicolumn{5}{|c|}{ S1_30\% } \\
\hline & $\begin{array}{l}\varepsilon_{p} \\
{[\% 0]}\end{array}$ & $\begin{array}{l}\varepsilon_{p}^{\prime} \\
{[\% 0]}\end{array}$ & $\begin{array}{c}\varepsilon_{f} \\
{[\% 0]}\end{array}$ & $\begin{array}{l}\Delta \varepsilon_{p} \\
{[\% 0]}\end{array}$ & $\begin{array}{c}\text { Loss } \\
{[\%]}\end{array}$ & $\begin{array}{c}\varepsilon_{p} \\
{[\% 0]}\end{array}$ & $\begin{array}{c}\varepsilon_{p}^{\prime} \\
{[\% 0]}\end{array}$ & $\begin{array}{l}\varepsilon_{f} \\
{[\% 0]}\end{array}$ & $\begin{array}{c}\Delta \varepsilon_{p} \\
{[\% 0]}\end{array}$ & $\begin{array}{c}\text { Loss } \\
{[\%]}\end{array}$ \\
\hline $25 \mathrm{~mm}$ & 2.657 & 2.710 & 2.110 & 0.600 & 23 & 4.020 & 3.802 & 2.855 & 0.947 & 24 \\
\hline $75 \mathrm{~mm}$ & 2.579 & 2.658 & 2.594 & 0.065 & 3 & 4.005 & 3.672 & 3.378 & 0.294 & 7 \\
\hline $125 \mathrm{~mm}$ & 2.632 & 2.691 & 2.658 & 0.032 & 1 & 4.089 & 3.886 & 3.791 & 0.094 & 2 \\
\hline $200 \mathrm{~mm}$ & 2.573 & 2.655 & 2.640 & 0.015 & 1 & 4.107 & 3.892 & 3.798 & 0.094 & 2 \\
\hline $850 \mathrm{~mm}$ & 2.619 & 2.710 & 2.690 & 0.021 & 1 & 4.103 & 3.864 & 3.784 & 0.080 & 2 \\
\hline $1050 \mathrm{~mm}$ & 2.627 & 2.709 & 2.695 & 0.015 & 1 & 4.116 & 3.891 & 3.832 & 0.059 & 1 \\
\hline $1975 \mathrm{~mm}$ & 2.603 & 2.698 & 2.668 & 0.029 & 1 & 4.101 & 3.871 & 3.759 & 0.112 & 3 \\
\hline $2025 \mathrm{~mm}$ & 2.603 & 2.712 & 2.626 & 0.085 & 3 & 4.107 & 3.874 & 3.659 & 0.215 & 5 \\
\hline outside & 2.602 & 2.767 & 0.152 & 2.615 & 100 & 4.100 & 3.858 & -0.017 & 3.875 & 95 \\
\hline Temperature $\left[{ }^{\circ} \mathrm{C}\right]$ & 19.5 & 2 & & & & 29.4 & & & & \\
\hline
\end{tabular}




\begin{tabular}{|c|c|c|c|c|c|c|c|c|c|c|}
\hline \multirow[b]{2}{*}{ Strain gauge } & \multicolumn{5}{|c|}{ S2_20\% } & \multicolumn{5}{|c|}{ S2_30\% } \\
\hline & $\begin{array}{c}\varepsilon_{p} \\
\%\end{array}$ & $\varepsilon_{p}^{\prime}$ & $\varepsilon_{f}$ & $\Delta \varepsilon_{p}$ & Loss & $\varepsilon_{p}$ & $\varepsilon_{p}^{\prime}$ & $\varepsilon_{f}$ & $\Delta \varepsilon_{p}$ & Loss \\
\hline $25 \mathrm{~mm}$ & 2.718 & 2.662 & 2.072 & 0.590 & 22 & 4.018 & 3.953 & 3.326 & 0.627 & 16 \\
\hline $100 \mathrm{~mm}$ & 2.684 & 2.628 & 2.575 & 0.053 & 2 & 3.968 & 3.897 & 3.871 & 0.027 & 1 \\
\hline $1850 \mathrm{~mm}$ & 2.667 & 2.612 & 2.585 & 0.026 & 1 & 4.000 & 3.912 & 3.923 & -0.012 & 0 \\
\hline \multirow[t]{2}{*}{ Temperature $\left[{ }^{\circ} \mathrm{C}\right]$} & 15.7 & \multicolumn{3}{|c|}{16.7} & & 16.9 & \multicolumn{2}{|c|}{17.4} & & \\
\hline & \multicolumn{5}{|c|}{ S2_40\% } & \multicolumn{5}{|c|}{ S2_50\% } \\
\hline Strain & $\begin{array}{l}\varepsilon_{p} \\
{[\% 0]}\end{array}$ & $\begin{array}{c}\varepsilon_{p}^{\prime} \\
{[\% 0]}\end{array}$ & $\begin{array}{l}\varepsilon_{f} \\
{[\% 0]}\end{array}$ & $\begin{array}{c}\Delta \varepsilon_{p} \\
{[\% 0]}\end{array}$ & $\begin{array}{c}\text { Loss } \\
{[\%]}\end{array}$ & $\begin{array}{c}\varepsilon_{p} \\
{[\% 0]}\end{array}$ & $\begin{array}{c}\varepsilon_{p}^{\prime} \\
{[\% 0]}\end{array}$ & $\begin{array}{c}\varepsilon_{f} \\
{[\% 0]}\end{array}$ & $\begin{array}{l}\Delta \varepsilon_{p} \\
{[\% 0]}\end{array}$ & $\begin{array}{c}\text { Loss } \\
{[\%]}\end{array}$ \\
\hline $25 \mathrm{~mm}$ & 5.388 & 5.291 & 3.355 & 1.935 & 36 & 6.499 & 6.475 & 5.075 & 1.400 & 22 \\
\hline $100 \mathrm{~mm}$ & 5.304 & 5.177 & 5.006 & 0.171 & 3 & 6.693 & 6.648 & 6.509 & 0.139 & 2 \\
\hline $1850 \mathrm{~mm}$ & 5.370 & 5.317 & 5.285 & 0.032 & 1 & 6.672 & 6.622 & 6.572 & 0.050 & 1 \\
\hline Temperature $\left[{ }^{\circ} \mathrm{C}\right]$ & 15.7 & \multicolumn{2}{|c|}{16.7} & & & 16.9 & \multicolumn{2}{|c|}{17.4} & & \\
\hline
\end{tabular}

$\Delta \varepsilon_{p}=\varepsilon_{f}-\varepsilon_{p}^{\prime} ;$ Loss $=\Delta \varepsilon_{p} / \varepsilon_{p} \times 100$ 


\begin{tabular}{|c|c|c|c|c|c|c|c|c|c|c|}
\hline \multirow[b]{2}{*}{ Strain gauge } & \multicolumn{5}{|c|}{ S3_20\% } & \multicolumn{5}{|c|}{ S3_30\% } \\
\hline & $\begin{array}{c}\varepsilon_{p} \\
\%\end{array}$ & $\varepsilon_{p}^{\prime}$ & $\varepsilon_{f}$ & $\Delta \varepsilon_{p}$ & Loss & $\varepsilon_{p}$ & $\varepsilon_{p}^{\prime}$ & $\varepsilon_{f}$ & $\Delta \varepsilon_{p}$ & Loss \\
\hline $25 \mathrm{~mm}$ & 2.704 & 2.740 & 2.281 & 0.459 & 17 & 4.009 & 3.721 & 3.224 & 0.497 & 12 \\
\hline $100 \mathrm{~mm}$ & 2.637 & 2.635 & 2.585 & 0.050 & 2 & 4.009 & 3.739 & 3.677 & 0.062 & 2 \\
\hline $1850 \mathrm{~mm}$ & 2.700 & 2.698 & 2.656 & 0.041 & 2 & 4.014 & 3.702 & 3.666 & 0.035 & 1 \\
\hline \multirow[t]{2}{*}{ Temperature $\left[{ }^{\circ} \mathrm{C}\right]$} & 20.6 & \multicolumn{3}{|c|}{23.3} & & 23.1 & \multicolumn{2}{|c|}{18.4} & & \\
\hline & \multicolumn{5}{|c|}{ S3_40\% } & \multicolumn{5}{|c|}{ S3_50\% } \\
\hline Strain & $\begin{array}{l}\varepsilon_{p} \\
{[\% 0]}\end{array}$ & $\begin{array}{c}\varepsilon_{p}^{\prime} \\
{[\% 0]}\end{array}$ & $\begin{array}{c}\varepsilon_{f} \\
{[\% 0]}\end{array}$ & $\begin{array}{c}\Delta \varepsilon_{p} \\
{[\% 0]}\end{array}$ & $\begin{array}{c}\text { Loss } \\
{[\%]}\end{array}$ & $\begin{array}{c}\varepsilon_{p} \\
{[\% 0]}\end{array}$ & $\begin{array}{c}\varepsilon_{p}^{\prime} \\
{[\% 0]}\end{array}$ & $\begin{array}{c}\varepsilon_{f} \\
{[\% 0]}\end{array}$ & $\begin{array}{c}\Delta \varepsilon_{p} \\
{[\% 0]}\end{array}$ & $\begin{array}{c}\text { Loss } \\
{[\%]}\end{array}$ \\
\hline $25 \mathrm{~mm}$ & 5.373 & 5.362 & 3.313 & 2.049 & 38 & 6.425 & 6.018 & 4.250 & 1.768 & 28 \\
\hline $100 \mathrm{~mm}$ & 5.376 & 5.401 & 5.206 & 0.195 & 4 & 6.416 & 6.047 & 5.908 & 0.139 & 2 \\
\hline $1850 \mathrm{~mm}$ & 5.329 & 5.327 & 5.265 & 0.062 & 1 & 7.087 & 6.453 & 6.391 & 0.062 & 1 \\
\hline Temperature $\left[{ }^{\circ} \mathrm{C}\right]$ & 20.6 & \multicolumn{2}{|c|}{23.3} & & & 23.1 & \multicolumn{2}{|c|}{18.4} & & \\
\hline
\end{tabular}

$\Delta \varepsilon_{p}=\varepsilon_{f}-\varepsilon_{p}^{\prime} ;$ Loss $=\Delta \varepsilon_{p} / \varepsilon_{p} \times 100$ 